\title{
TBDY-2018 VE DBYBHY-2007 DEPREM YÖNETMELİKLERİ PERFORMANS SEVIYELERINININ KARŞILAŞTIRILMASI
}

\author{
Bayram Tanık ÇAYCI*, Osman ELDEMIR
}

Pamukkale Üniversitesi, Mühendislik Fakültesi, İnșaat Mühendisliği Bölümü, Denizli, Türkiye

\begin{tabular}{l} 
Anahtar Kelimeler \\
\hline TBDY-2018, \\
DBYBHY-2007, \\
Betonarme Yapılar, \\
Sismik Performans, \\
Doğrusal Olmayan Analiz.
\end{tabular}

Doğrusal Olmayan Analiz.

\begin{abstract}
Öz
Gerçekleştirilen çalışmanın amacı Türk Bina Deprem Yönetmeliği-2018 ve Deprem Bölgelerinde Yapılacak Binalar Hakkında Yönetmelik-2007'de tanımlı bina performans seviyelerinin karşılaştırılmasıdır. Bu kapsamda daha önce inşa edilmiş 5 farklı betonarme bina bilgisayar ortamında modellenmiştir. Doğrusal olmayan davranış özellikleri eleman uçlarında tanımlanan kullanıcı tanımlı plastik mafsallar ile modele yansıtılmıştır. Statik itme analizi gerçekleştirilen modellerin farklı ötelenme oranları için performans düzeyleri hesaplanmıştır. Elde edilen sonuçlar değerlendirildiğinde her iki yönetmeliğin kesit hasar sınır tanımlarının büyük farklılıklar içerdiği görülmektedir. TBDY-2018 Sınırlı Hasar performans düzeyine karşılık gelen çatı katı deplasman değeri DBYBHY-2007 Hemen Kullanım performans düzeyine göre ortalama \%100 daha düşük hesaplanmıştır. Kontrollü Hasar ve Göçme Öncesi performans düzeylerine de Can Güvenliği ve Göçmenin Önlenmesi performans düzeylerine göre sırasıyla \%25 ve \%33 daha düşük deplasman değerleri altında ulaşılmaktadır. Dikkat çeken bir diğer nokta da Sınırlı Hasar performans düzeyine sistemin akma noktasından önce ulaşılmış olmasıdır. TBDY-2018'de çatlamış kesit rijitliği tanımındaki değişime bağlı olarak bina baskın titreşim periyotları genellikle daha düşük hesaplanmaktadır. Bu duruma bağlı olarak kapasite eğrilerinin eğimi ve plastik mafsal desenleri de farklılık göstermektedir. Her iki yönetmelik arasında hasar düzeyi tanımlarında önemli farkların olması nedeniyle, DBYBHY-2007 kriterlerine göre performans incelemesi gerçekleştirilen yapıların TBDY-2018 kriterlerine göre yetersiz düzeyde çıkması ihtimali bulunmaktadır.
\end{abstract}

\section{COMPARISONS OF PERFORMANCE LIMIT STATES OF TEC-2018 AND TEC- 2007 SEISMIC CODES}

\begin{tabular}{ll}
\hline Keywords & Abstract \\
\hline TEC-2018, & This study aims to compare building performance levels defined in the Turkish \\
TEC-2007, & Building Earthquake Code-2018 and 2007. For this purpose, 5 RC residential \\
RC Structures, & buildings were modeled in computer environment. Nonlinear behavior of structural \\
Seismic Performance, & members was reflected to the models by using user-defined plastic hinges. \\
Nonlinear Analysis. & Performance levels of building models was obtained with static pushover analyzes \\
at different roof drift ratios. It is seen that the definition of section damage limits of & both regulations has remarkable differences. The roof displacement limit \\
corresponding to TEC-2018 Limited Damage level were calculated 100\% lower than & TEC-207 Immediate Occupancy damage level on average. Controlled Damage and \\
& Pre-Collapse performance levels are also reached at 25\% and 33\% lower roof \\
& displacement values than Life Safety and Collapse Prevention performance levels, \\
& respectively. Another point should be emphasis is that the Limited Damage \\
performance level has been reached before yield point of capacity curve. The slope & of capacity curves and damage pattern of building models also vary due to change \\
in definition of cracked section stiffness in TEC-2018. There is a possibility that the & buildings with performance assessment were carried out according to TEC-2007 \\
may be inadequate according to TEC-2018 considering significant differences in \\
damage level definitions.
\end{tabular}

\footnotetext{
* ilgili yazar / Corresponding author: bcayci@pau.edu.tr
} 


\section{Alıntı / Cite}

Çaycı, B. T., Eldemir, O., (2021). TBDY-2018 ve DBYBHY-2007 Deprem Yönetmelikleri Performans Seviyelerinin Karşlaştırılması, Mühendislik Bilimleri ve Tasarım Dergisi, 9(4), 1386-1397.

\begin{tabular}{l|l|l}
\hline Yazar Kimliği / Author ID (ORCID Number) & Makale Süreci / Article Process \\
\hline B. T. Çaycl, 0000-0001-7520-6490 & Başvuru Tarihi / Submission Date & 08.02 .2021 \\
O. Eldemir, 0000-0002-7791-085X & Revizyon Tarihi / Revision Date & 23.08 .2021 \\
& Kabul Tarihi / Accepted Date & 16.09 .2021 \\
& Yayım Tarihi / Published Date & 20.12 .2021 \\
\hline
\end{tabular}

\section{Giriş (Introduction)}

1 Ocak 2019 tarihinde Deprem Bölgelerinde Yapılacak Binalar Hakkında Yönetmelik (DBYBHY, 2007) yürürlükten kalkarak Türk Bina Deprem Yönetmeliği (TBDY, 2018) yürürlüğe girmiştir. Yeni yönetmelikle birlikte binaların tasarım ve değerlendirme aşamalarında köklü bir değişikliğe gidilmiştir. Yeni yönetmelikle birlikte hem yapıların sismik tasarımı hem de mevcut yapıların değerlendirilmesi konusunda birçok köklü değișiklik yapılmıștır. Yenilenen Türkiye deprem haritası ile tasarım ve değerlendirmede kullanılacak olan sismik talepler için deprem bölgeleri kavramı ve sabit yer ivmesi büyüklükleri yerine spektral ivme katsayıları yapının bulunduğu konum için hesaplanmaktadır. Ayrıca özel tasarım kuralları gerektiren sismik yalıtımlı binalar ve yüksek binalar için ilave bölümler eklenmiştir.

TBDY-2018'de yapılan önemli değișikliklerden birisi de yığılı plastik mafsal kesit hasar sınırlarının plastik dönme kapasitelerine göre belirlenmesidir. DBYBHY-2007'de ise kesit hasar sınırları beton ve donatı çeliğinin birim şekil değiştirmeleri cinsinden hesaplanmaktaydı. Eurocode-8 (2004) ile büyük benzerlik gösteren yeni hasar sınırı tanımları doğal olarak önceki yönetmeliğe göre büyük farklılıklar göstermektedir.

DBYBHY-2007 ilkelerine göre mevcut yapıların performansının değerlendirilmesi konusunda geçmiște birçok çalışma yapılmış olmasına rağmen (Sucuoğlu, 2007; Özmen, 2011; Safkan, 2012; Özmen vd., 2015), henüz yeni bir yönetmelik olması nedeniyle TBDY-2018 ile ilgili literatürde sınırlı düzeyde çalışma bulunmaktadır (Elçi ve Göker, 2018; Ulutaş, 2019; Sümer ve Hamsici, 2020; Foroughi vd., 2020). Bununla birlikte performans değerlendirmesi DBYBHY-2007 kriterlerine göre yapılan birçok yapının güncel yönetmelik şartlarına göre hangi performans düzeyinde olacağı bilinmemektedir. Dolayısıyla önceki yönetmeliğe göre yapılan bir yapının güncel kriterlere göre yeniden değerlendirilmesinin gerekli olup olmadığı sorusu ortaya çıkmaktadır.

Gerçekleştirilen çalışmanın amacı TBDY-2018 ve DBYBHY-2007'de tanımlı hasar sınırlarının mevcut betonarme yapılar dikkate alınarak karşılaştırılmasıdır. Bu kapsamda daha önce inşa edilmiş 5 adet betonarme bina bilgisayar ortamında modellenerek statik itme analizleri gerçekleştirilmiştir. Statik analiz sonrası farklı çatı katı göreli ötelenme oranlarına göre taşıyıcı sistem elemanlarının hasar seviyeleri her iki yönetmelik için karşılaştırılarak sonuçlar değerlendirilmiştir.

\section{Kesit Hasar Sınırları ve Performans Düzeylerinin Tanımlanması (Defining of section damage limits and performance levels)}

\subsection{Kesit Hasar Sınırları (Section damage limits)}

DBYBHY-2007'de Minimum Hasar Sınırı (MN), Güvenlik Sınırı (GV) ve Göçme Sınırı (GÇ) olmak üzere üç kesit hasar sınırı tanımlanmaktadır. Minimum Hasar noktası, doğrusal olmayan davranışın başlangıç sınırı olarak tarif edilmektedir. Güvenli sınırlar içerisinde meydana gelen plastik şekil değiştirme sınırı Güvenlik Sınırı, göçme öncesi hesaplanan plastik şekil değirme kapasitesi ise Göçme Sınırı olarak tarif edilmektedir. Kesit hasar sınırları için birim şekil değiştirme kapasiteleri Tablo 1'de verilmiștir. DBYBHY-2007'ye göre ilgili kesit hasar sınırlarına göre hesaplanan hasar bölgeleri ise Şekil 1'de yer almaktadır.

Tablo 1. DBYBHY-2007 eleman birim șekil değiștirme kapasiteleri (TEC-2007 section unit deformation capacities)

\begin{tabular}{ccc}
\hline $\begin{array}{c}\text { Hasar } \\
\text { Sinırı }\end{array}$ & Beton & Donatı Çeliği \\
\hline MN & $\left(\varepsilon_{\mathrm{cu}}\right)_{\mathrm{MN}}=0.0035$ & $\left(\varepsilon_{\mathrm{s}}\right)_{\mathrm{MN}}=0.010$ \\
$\mathrm{GV}$ & $\left(\varepsilon_{\mathrm{cg}}\right)_{\mathrm{GV}}=0.0035+0.01\left(\rho_{\mathrm{s}} / \rho_{\mathrm{sm}}\right)$ & $\left(\varepsilon_{\mathrm{s}}\right)_{\mathrm{GV}}=0.040$ \\
& $\leq 0.0135$ & \\
$\mathrm{GC}$ & $\left(\varepsilon_{\mathrm{cg}}\right)_{\mathrm{GC}}=0.004+0.014\left(\rho_{\mathrm{s}} / \rho_{\mathrm{sm}}\right)$ & $\left(\varepsilon_{\mathrm{s}}\right)_{\mathrm{GC}}=0.060$ \\
\hline
\end{tabular}




\section{İç Kuvvet}

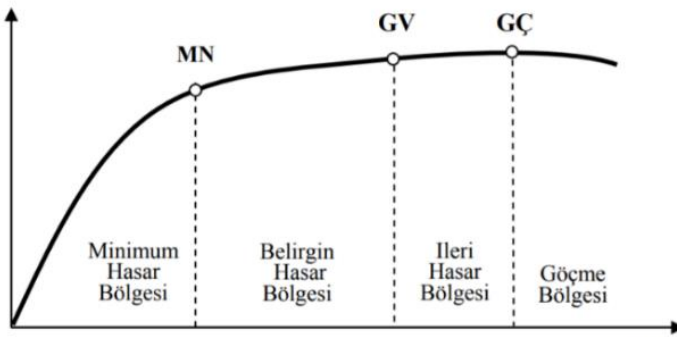

Şekildeğiştirme

Şekil 1. DBYBHY-2007 kesit hasar bölgeleri (TEC-2007 Sectional damaged areas)

TBDY-2018'de ise Sınırlı Hasar (SH), Kontrollü Hasar (KH) ve Göçme Öncesi (GÖ) olmak üzere üç farklı kesit hasar sınırı tanımlanmaktadır. Göçmenin önlenmesi kesit hasar sınırı için hesaplanan dönme kapasitesi Denklem (1)’e göre hesaplanmaktadır. Kontrollü Hasar sınırı, Göçme Öncesi kesit dönme kapasitesinin \%75'i olarak tanımlanmaktadır. Sınırlı Hasar düzeyi ise kesitin elastik dönme sınırı olarak tarif edilmektedir. TBDY-2018'de tanımlı kesit hasar bölgeleri Şekil 2'de yer almaktadır.

$$
\begin{gathered}
\theta_{\mathrm{p}}^{(\mathrm{GO})}=\frac{2}{3}\left[\left(\phi_{\mathrm{u}}-\phi_{\mathrm{y}}\right) \mathrm{L}_{\mathrm{p}}\left(1-0.5 \frac{\mathrm{L}_{\mathrm{p}}}{\mathrm{L}_{\mathrm{s}}}\right)+4.5 \phi_{\mathrm{u}} \mathrm{d}_{\mathrm{b}}\right] \\
\theta_{\mathrm{p}}{ }^{(\mathrm{KH})}=0.75 \theta_{\mathrm{p}}{ }^{(\mathrm{GO})} ; \theta_{\mathrm{p}}{ }^{(\mathrm{SH})}=0
\end{gathered}
$$

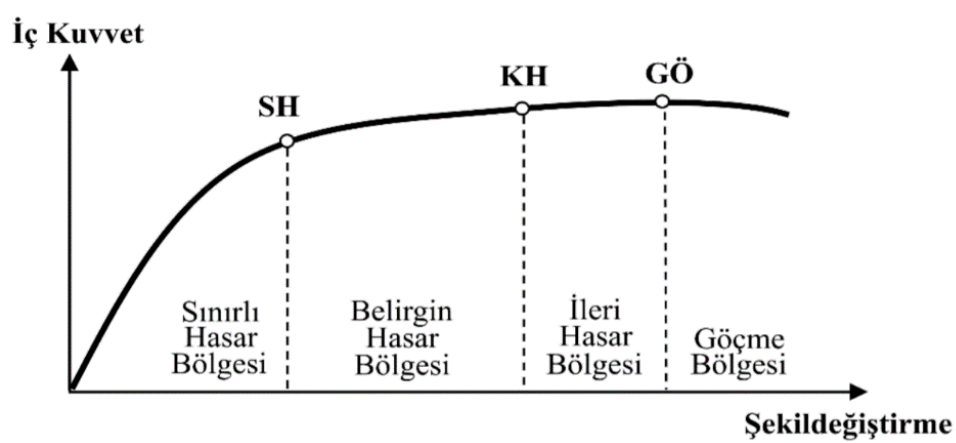

Şekil 2. TBDY-2018 kesit hasar bölgeleri (TEC-2018 Sectional damaged areas)

\subsection{Performans seviyeleri (Performance levels)}

TBDY-2018 için yapı performansı sınır değerleri Sınırlı Hasar (SH), Kontrollü Hasar (KH) ve Göçmenin Önlenmesi (GÖ) olarak üç noktada tanımlanmaktadır. Benzer şekilde DBYBHY-2007'de bu sınır değerler Hemen Kullanım (HK), Can Güvenliği (CG) ve Göçme Öncesi (GÖ) olarak adlandırılmaktaydı. Tablo 2'de her iki yönetmelik hedef performans düzeyleri kısaca özetlenmiştir. Tablo 2 incelendiğinde tanım olarak Hemen Kullanım-Sınırlı Hasar noktaları dıșında bir değișikliğe gidilmediği söylenebilir. Sınırlı Hasar performans düzeyi belirgin hasar düzeyinde kiriş eleman yüzdesi \%20 iken Hemen Kullanım performans düzeyinde bu oranın \%10 olduğu görülmektedir.

\begin{tabular}{|c|c|c|}
\hline \multicolumn{3}{|c|}{ DBYBHY-2007 } \\
\hline \multirow[t]{2}{*}{ Performans Düzeyi } & \multicolumn{2}{|c|}{ İzin verilen hasar oranı } \\
\hline & Kolon & Kiriş \\
\hline Hemen Kullanım (HK) & Tamamı MH & $\mathrm{BH}(\% 10)$ \\
\hline Can Güvenliği (CG) & İH $(\% 20)$ & İH $(\% 30)$ \\
\hline Göçme Öncesi (GÖ) & Tamami < & $\mathrm{GB}(\% 20)$ \\
\hline \multicolumn{3}{|c|}{ TBDY-2018 } \\
\hline \multirow[t]{2}{*}{ Performans Düzeyi } & \multicolumn{2}{|c|}{ İzin verilen hasar oranı } \\
\hline & Kolon & Kiriş \\
\hline Sinırlı Hasar (SH) & Tamamı SH & $\mathrm{BH}(\% 20)$ \\
\hline Kontrollü Hasar (KH) & İH $(\% 20)$ & İH (\%35) \\
\hline Göçmenin Önlenmesi GÖ) & Tamamı < & $\mathrm{GB}(\% 20)$ \\
\hline
\end{tabular}

Tablo 2. Performans düzeyi hasar sınırları (Targeted damage levels) 


\section{Bina özellikleri ve modelleme (Building properties and modelling)}

Gerçekleştirilen çalışmada daha önce inşa edilmiş 5 farklı betonarme bina kullanılmıştır (Eldemir, 2019). Binalar mevcut statik ve mimari projeleri ve yükler dikkate alınarak bilgisayar ortamında modellenmiștir. Analizler Sap2000 (CSI, 2018) programı ile gerçekleștirilmiştir. Çalışmada dikkate alınan binaların tamamı ABYYHY-1998 ve DBYBHY-2007 kriterlerine göre tasarlanmıștır. Kullanılan modellerin tamamında ilgili yönetmelik kriterlerine uygun olarak eleman uçlarında sargılama bölgesi oluşturulmuştur. Modellenen binalara ait bilgiler Tablo 3'te kısaca özetlenmiştir.

Tablo 3. Bina genel özellikleri (Building properties)

\begin{tabular}{|c|c|c|c|c|c|}
\hline & $\begin{array}{l}\text { Beton } \\
\text { Sinifi }\end{array}$ & Donatı Sinıfı & $\begin{array}{l}\text { Kat } \\
\text { Sayısı }\end{array}$ & $\begin{array}{l}\text { Kat Yüksekliği } \\
(\mathrm{m})\end{array}$ & $\begin{array}{l}\text { Bina Yüksekliği } \\
(\mathrm{m})\end{array}$ \\
\hline Model 1 & $\mathrm{C} 20 / 25$ & BÇIII (S420) & 4 & 2.9 & 11.6 \\
\hline Model 2 & $\mathrm{C} 20 / 25$ & BÇIII (S420) & 5 & $\begin{array}{c}2.5 \text { (1. ve } 2 \text {. Kat }) \\
2.3 \text { (3.Kat) } \\
2.8 \text { (4. ve } 5 . \text { Kat })\end{array}$ & 12.9 \\
\hline Model 3 & $\mathrm{C} 25 / 30$ & BÇIII (S420) & 4 & 2.8 & 11.2 \\
\hline Model 4 & $\mathrm{C} 25 / 30$ & BÇIII (S420) & 5 & $\begin{array}{c}2.7 \text { (1.,3.,4.,5. Kat) } \\
4.4 \text { (2. Kat) }\end{array}$ & 15.2 \\
\hline Model 5 & $\mathrm{C} 20 / 25$ & BCIII (S420) & 6 & 2.8 & 16.8 \\
\hline
\end{tabular}

Yapısal elemanlar için çatlamış kesit rijitliği değerleri ilgili yönetmeliğin kriterleri dikkate alınarak uygulanmıştır. DBYBHY-2007'de tanımlı çatlamış kesit rijitliği hesabı kiriş elemanlar için Denklem 3, kolon elemanlar için eksenel yük oranına göre Denklem 4 ve 5'e göre yapılmıştır. Kolon elemanlar için ara değerler enterpolasyon ile hesaplanmıştır.

$$
\begin{gathered}
\text { Kiriş elemanlar için: } \\
(\mathrm{EI})_{\mathrm{e}}=0.40(\mathrm{EI})_{0} \\
\text { Kolon Elemanlar İçin: } \\
\mathrm{N}_{\mathrm{D}} /\left(\mathrm{A}_{\mathrm{c}} \mathrm{f}_{\mathrm{cm}}\right) \leq 0.10 \text { ise: } \\
(\mathrm{EI})_{\mathrm{e}}=0.40(\mathrm{EI})_{0} \\
\mathrm{~N}_{\mathrm{D}} /\left(\mathrm{A}_{\mathrm{c}} \mathrm{f}_{\mathrm{cm}}\right) \geq 0.40 \text { ise: } \\
(\mathrm{EI})_{\mathrm{e}}=0.80(\mathrm{EI})_{0}
\end{gathered}
$$

TBDY-2018 ile etkin kesit rijitliği hesabı da değişmiştir. Kolon elemanlar için eksenel yük düzeyinden bağımsız olarak etkin kesit rijitliği çarpanı 0.70 , kirişlerde ise 0.35 alınmaktadır. Tablo 4'te tüm elemanlar için etkin kesit rijitliği çarpanları yer almaktadır.

Yapısal elemanların doğrusal olmayan davranış özellikleri plastik mafsallar yardımıyla modellere yansıtılmıştır. Plastik mafsal özelliklerini analiz programları otomatik olarak tanımlayabilmektedir. Bu seçenek modellerin oluşturulması için gerekli iş yükünü büyük oranda azaltması nedeniyle tercih edilmektedir. Ancak özellikle mevcut binaların doğrusal olmayan davranış özelliklerinin yansıtılmasında otomatik plastik mafsal tanımı yetersiz kalmakta, kullanıcı tanımlı plastik mafsalların kullanılması önerilmektedir (İnel ve Özmen, 2006). Bu nedenle çalışmada kullanılan binaların doğrusal olmayan davranış özellikleri kullanıcı tanımlı plastik mafsallar kullanılarak modellere yansıtılmıștır.

Kullanıcı tanımlı plastik mafsal özelliklerinin belirlenebilmesi için her bir taşıyıcı elemana ait moment-eğrilik analizleri SEMAp programı yardımıyla Mander sargılı beton davranışı modeli (Mander vd., 1988) kullanılarak gerçekleștirilmiştir (Kumbasaroğlu, 2020). Moment-eğrilik davranışları elde edilen elemanların plastik mafsal hasar sınırları DBYBHY-2007 ve TBDY-2018 kriterlerine uygun olarak hesaplanmıștır. Plastik mafsallar eleman alt ve üst uçlarına kesit yüksekliğinin yarısı kadar uzaklıkta atanmıştır. Yapısal elemanlarda gevrek davranış beklenmediği için kesme ve eksenel yük mafsalları tanımlanmamıștır. Her bir bina için yönetmelik plastik mafsal hasar hesaplarına göre hazırlanan iki farklı model oluşturularak kritik çerçeve aksı için statik analizler gerçekleștirilmiştir. Statik itme analizlerinde düşük-orta katlı binalarda en etkin talep dağılımı veren dikdörtgen yük deseni tercih edilmiştir (Korkmaz vd., 2006). 
Tablo 4. TBDY-2018 etkin kesit rijitliği çarpanları (TEC-2018 effective section stifness coefficients)

\begin{tabular}{ccc}
\hline Betonarme Taşıyıcı Sistem Elemanı & Etkin Kesit Rijitliği Çarpanı \\
\hline Perde-Döșeme (Düzlem İçi) & Eksenel & Kayma \\
Perde & 0.50 & 0.50 \\
Bodrum perdesi & 0.80 & 0.50 \\
Döşeme & 0.25 & 0.25 \\
Perde-Döşeme (Düzlem Dışı) & Eğilme & Kesme \\
Perde & 0.25 & 1.00 \\
Bodrum perdesi & 0.50 & 1.00 \\
Döşeme & 0.25 & 1.00 \\
Çubuk Eleman & Eğilme & Kesme \\
Bağ Kirişi & 0.15 & 1.00 \\
Çerçeve Kirişi & 0.35 & 1.00 \\
Çerçeve Kolonu & 0.70 & 1.00 \\
Perde (eşdeğer çubuk) & 0.50 & 0.50 \\
\hline
\end{tabular}

\section{Bulgular (Findings)}

\subsection{Hakim titreșim periyotlarının karșılaştırılması (Comparison of of dominant vibration periods )}

Her iki yönetmelikte çatlamış kesit rijitliği tanımları farklı olduğu için bina titreşim periyotları da değişkenlik göstermektedir. Tablo 5'te modal analiz sonucu elde edilen hakim titreșim periyotlarının her iki yönetmelik için karşılaştırılması her almaktadır. Tablo 5 incelendiğinde Model 4 dışındaki binalarda iki yönetmelik için hesaplanan doğal titreşim periyot oranlarının 0.98 ile 1.10 arasında değiștiği görülmektedir. Model 4'te asma kat kullanılması ve kolon eksenel yük oranlarının da düşük olmasına bağlı olarak iki yönetmelik arasındaki oran 1.15 olarak hesaplanmıştır. Genel olarak DBYBHY-2007'de çatlamış kesit rijitliği hesabı kolon elemanlar için eksenel yük oranına göre yapıldığı için eksenel yük oranı düşük sistemlerde hesaplanan periyot değerleri TBDY-2018'e oranla daha yüksektir. İki yönetmelik arasındaki farkın özellikle eksenel yük düzeyi düşük yapılarda daha da artacağı öngörülebilir.

Tablo 5. Bina hakim periyotları (Dominant vibration periods)

\begin{tabular}{cccc}
\hline & \multicolumn{2}{c}{ Bina Hakim Periyodu } & Oran \\
Model & DBYBHY-2007 & TBDY- & \\
\hline Model 1 & 0.59 & 0.55 & 1.07 \\
Model 2 & 0.68 & 0.66 & 1.03 \\
Model 3 & 0.67 & 0.61 & 1.10 \\
Model 4 & 0.97 & 0.84 & 1.15 \\
Model 5 & 1.25 & 1.28 & 0.98 \\
\hline
\end{tabular}

\subsection{Kapasite eğrileri ve performans sınırlarının karşılaştırılması (Comparison of capacity curves and performance limits)}

Statik itme analizi sonrası her iki yönetmelik için hazırlanan modellerden elde edilen kapasite eğrileri ve yönetmelik performans sınırları bu bölümde karşılaştırılmıştır. Yönetmelik performans düzeyi sınır değerleri her bir bina için, taşıyıcı elemanların hasar düzeyleri hesaplanarak ilgili sınıra ulaştığı an belirlenmiştir.

Tablo 6'da performans sınır değerlerine ulaşıldığı ana karşılık gelen çatı katı deplasmanları verilmektedir. Şekil 3'te ise bu değerlerin birbirine oranları görülmektedir. Sonuçlar incelendiğinde TBDY-2018'de tanımlı Sınırlı Hasar performans noktasının Hemen Kullanım performans noktasına oranla çok daha düșük çatı katı deplasmanları altında ulaşıldığı görülmektedir. SH düzeyinin plastik bölge sınırı olması nedeniyle kiriș elemanların MN düzeyine oranla daha düşük kesit dönmeleri altında bu sınıra ulaştığı söylenebilir. Şekil 3'te de görüldüğü gibi Hemen Kullanım/Sınırlı Hasar çatı deplasman oranı ortalama 2.1 olarak hesaplanmıştır. İki performans noktası arasındaki oran 2.4 'e kadar çıkmaktadır. İzin verilen kiriş hasar yüzdesi \%10'dan \%20'ye çıkmasına rağmen performans sınır noktasına daha düşük talepler altında ulaşılması dikkat çekicidir. Kullanılan binalar için Can Güvenliği/Kontrollü Hasar ve Göçme Öncesi/Göçmenin önlenmesi çatı deplasman oranları ortalamaları sırasıyla 1.26 ve 1.33 olarak bulunmuştur. 
Tablo 6. Performans noktalarına karşılık gelen çatı deplasmanları (Roof displacement values that corresponded to performance limits)

\begin{tabular}{lllllll}
\hline \multirow{2}{*}{ Bina Adı } & \multicolumn{3}{c}{ DBYBHY-2007 (mm) } & \multicolumn{3}{c}{ TBDY-2018 (mm) } \\
& HK & GG & GÖ & SH & KH & GÖ \\
\hline Model 1 & 37.17 & 174.95 & 268.28 & 20.68 & 134.72 & 181.39 \\
Model 2 & 36.88 & 158.78 & 188.43 & 15.20 & 117.54 & 136.62 \\
Model 3 & 35.88 & 213.42 & 300.09 & 14.77 & 175.44 & 228.77 \\
Model 4 & 51.96 & 168.36 & 221.69 & 21.46 & 136.97 & 176.97 \\
Model 5 & 52.08 & 146.08 & 186.08 & 36.86 & 122.10 & 151.91 \\
\hline
\end{tabular}

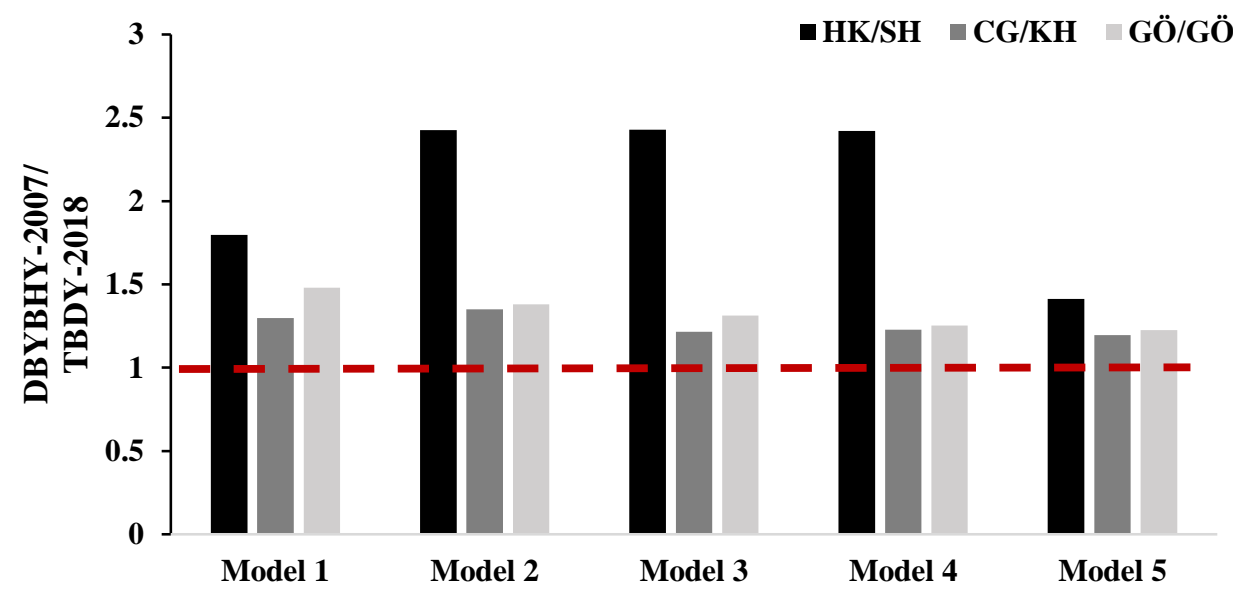

Şekil 3. Performans noktalarına karşılık gelen çatı deplasman oranları (The ratio of roof displacement values that corresponded to performance limits)

Şekil 4-8'de yönetmelik performans noktaları elde edilen kapasite eğrileri üzerinde verilmektedir. Çatlamış kesit rijitliği tanımındaki farklılık nedeniyle DBYBHY-2007 modellerinin daha düşük eğilme rijitliğine sahip olduğu görülmektedir. Ancak gözlenen fark sınırlı düzeydedir.

Kapasite eğrileri incelendiğinde, moment eğrilik analizi sonucu hesaplanan kesit akma noktalarının değişmemesi nedeniyle yapı akma noktaları da büyük oranda benzerlik göstermektedir. Ancak çatlamış kesit rijitliği tanımlarındaki farklılıklara bağlı olarak eğrilerinin eğimlerinde sınırlı düzeyde ayrışma gözlemlenmektedir. Dikkat çeken bir diğer fark ise, Sınırlı Hasar performans noktasına bina akma noktasından önce ulaşılmış olmasıdır (Balıkçı, 2019). Hemen Kullanım performans noktası ise kapasite eğrisi üzerinde yapı akma anına karşlık gelmektedir.

TBDY-2018 Bölüm 15.7.1.4'e göre talep kesme kuvveti (Ve)' nin Kesme Kapasitesine oranı 1.30'dan büyükse șekil değiştirme üst sınırları 0.50 ile çarpılarak azaltılmaktadır. Nervürsüz donatı kullanılması durumunda ise donatı çeliği birim şekil değiştirme ve plastik dönme talebi 1.5 ile çarpılarak arttırılmaktadır (Bölüm 15.7.1.2). Dolayısıyla ABYBHY-1997 yönetmeliğinden önce inşa edilmiș yapılar için performans hedef noktalarının bu çalıșmada hesaplanan deplasman değerlerinin oldukça altında hesaplanacağı söylenebilir. Başka bir ifadeyle sünek yapım kriterlerine göre inşa edilmemiş mevcut yapıların TBDY-2018 kriterlerini sağlaması DBYBHY-2007 yönetmeliğine oranla daha düşük bir ihtimaldir. 


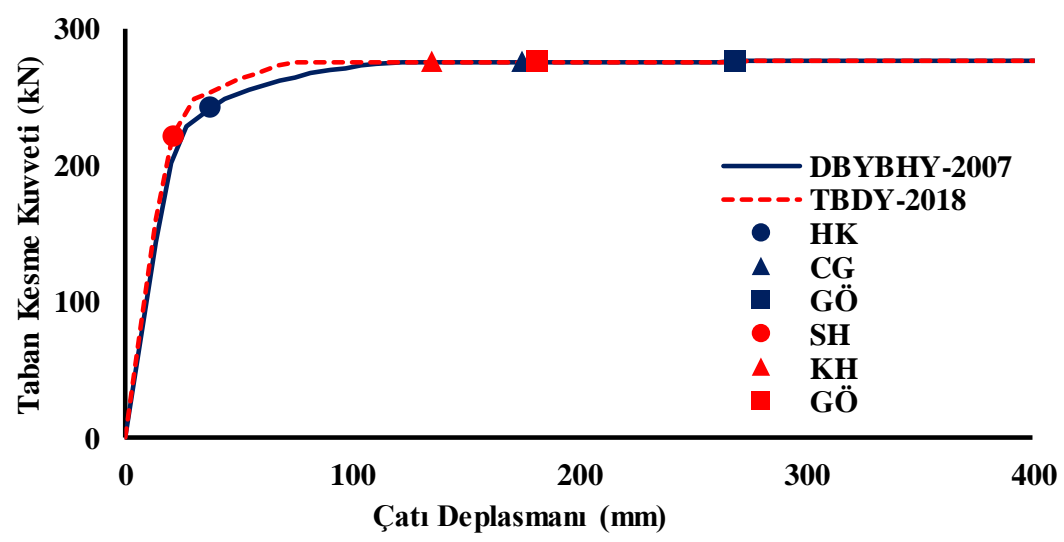

Şekil 4. Model 1'e ait kapasite eğrilerinin karşılaştırması (Comparison of capacity curves of model 1)

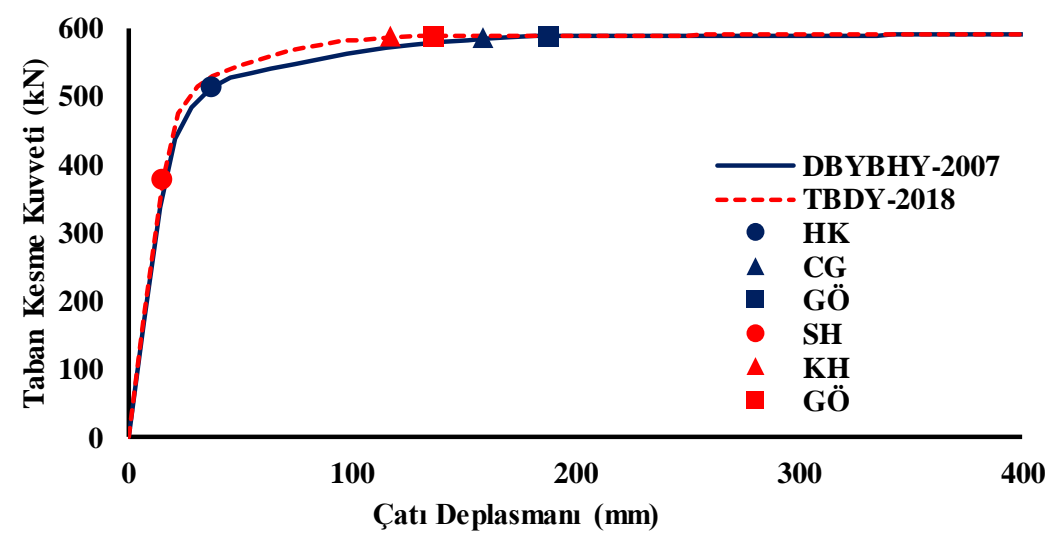

Şekil 5. Model 2'ye ait kapasite eğrilerinin karşılaştırması (Comparison of capacity curves of model 2)

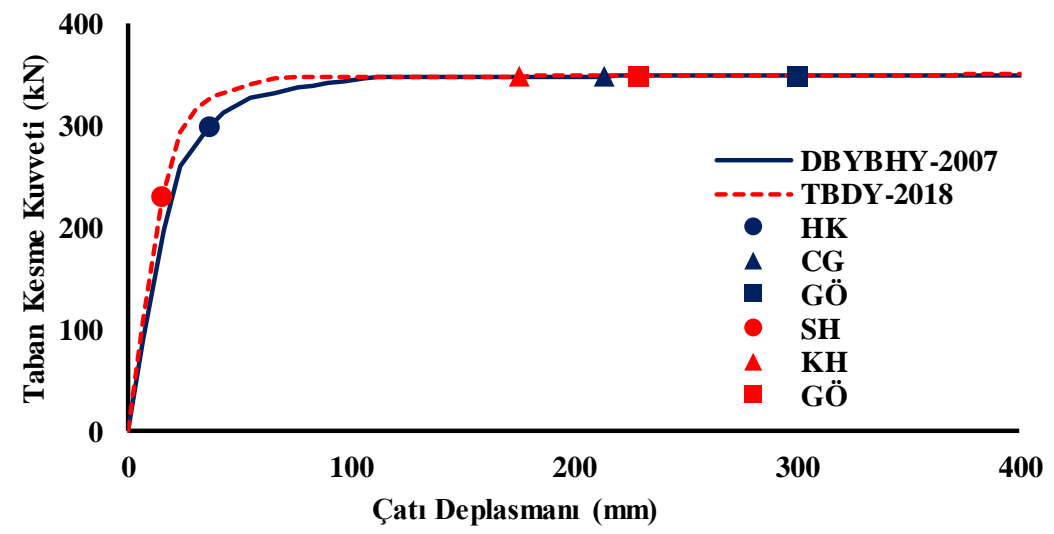

Şekil 6. Model 3'e ait kapasite eğrilerinin karşılaştırması (Comparison of capacity curves of model 3) 


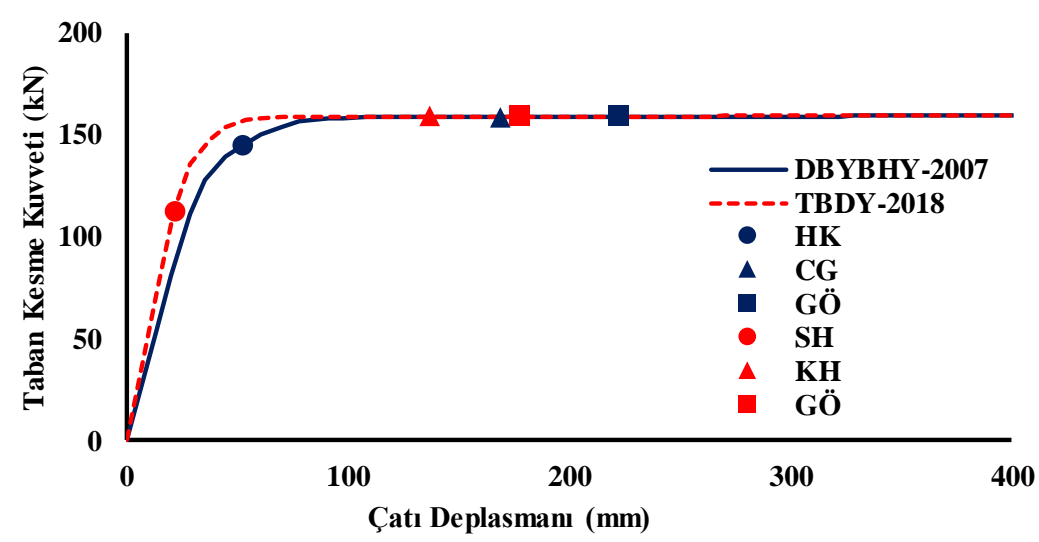

Şekil 7. Model 4'e ait kapasite eğrilerinin karşılaștırması (Comparison of capacity curves of model 4)

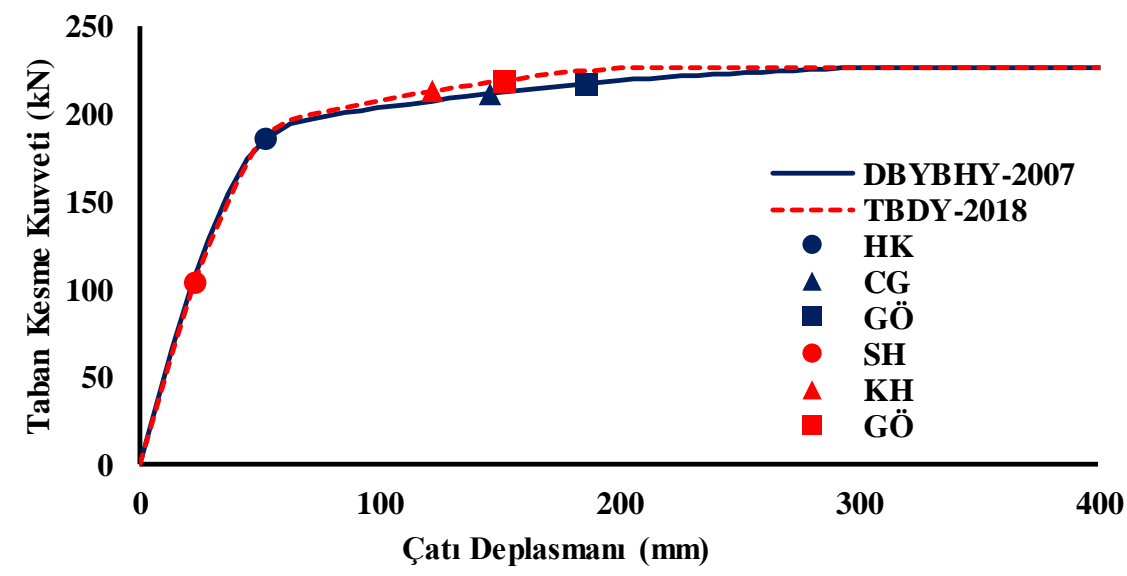

Şekil 8. Model 5'e ait kapasite eğrilerinin karşılaştırması (Comparison of capacity curves of model 4)

\subsection{Plastik mafsal hasar düzeylerinin karşılaştırılması (Comprasion of plastic hinge damage states)}

Şekil 9-11'de tüm modellere ait \%1.0, \%1.5 ve \%2.0 çatı katı ötelenme oranları için edilen ortalama plastik mafsal hasar dağılımları karşılaştırılmıştır. Sonuçlar incelendiğinde beklendiği gibi TBDY-2018 yönetmeliğine göre hazırlanan modellerin hasar oranlarını DBYBHY-2007 modellerine göre daha yüksek olduğu görülmektedir. \%1 çatı katı ötelenme oranı altında DBYBH-2007 modelleri için MH hasar düzeyindeki kirișlerin oranı \%17.08 iken, TBDY-2018 modellerinin tamamının SH hasar düzeyini aștığı görülmektedir. Benzer bir durum kolon elemanlar için de gözlemlenmektedir.

TBDY-2018 modelleri GB düzeyindeki kolon oranları \%1.0, \%1.5 ve \%2.0 çatı katı ötelenme oranları için sırasıyla \%1.11, \%7.10 ve \%16.28 olarak hesaplanmıștır. DBYBHY-2007 modelleri için aynı oranlar \%0.0, \%4.67 ve \%10.44 bulunmuștur. Her iki yönetmelik için yalnız plastik mafsal hasar oranları değil plastik mafsal desenleri de farklılık göstermektedir. Çatlamış kesit rijitliği tanımlarındaki farklılığın bu duruma neden olduğu tahmin edilmektedir. DBYBHY-2007'ye göre tanımlanan kolon çatlamış kesit rijitlikleri üst katlara doğru gidildikçe eksenel yük oranına bağlı olarak azalmaktadır. TBDY-2018'de ise tüm katlar için kolon etkin kesit rijitliği çarpanı 0.70 alınmaktadır.

Şekil 12-14'te Model 2 binası plastik mafsal dağılımları, \%1.0, \%1.5 ve \%2.0 çatı katı ötelenme oranları için örnek olarak verilmiştir. \%1.0 çatı ötelenme oranı altında TBDY-2018 binası son katında iki kiriş eleman Belirgin Hasar düzeyindeyken DBYBHY-2007 modelinde kiriş elemanlarda herhangi bir mafsal oluşumu gözlemlenmemiștir. 3. ve 4. katta TBDY-2018 binası için 6 kolon elemanın 4'ü Belirgin Hasar düzeyindedir. DBYBHY-2007 binası içinse aynı katlarda 2 kolon elemanın Minimum Hasar düzeyinde olduğu görülmektedir. Her iki yönetmeliğe göre tasarlanan binalarda kesit hasar noktalarının farklılık göstermesinin yanı sıra taşıyıcı elemanların eğilme rijitliklerinin farklı olması hasar dağılımlarını da belirli ölçüde değiştirebilmektedir. Hasar mekanizması için gözlenen bu farklılıkların özellikle dinamik analiz yöntemleri için daha da artabileceği ön görülmektedir (Eldemir, 2019). 


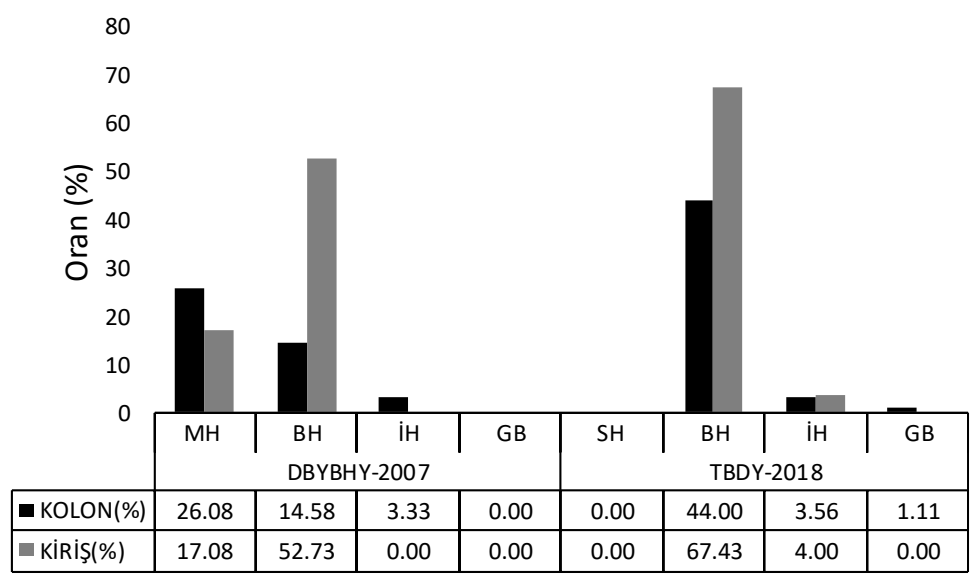

Şekil 9. \%1 Çatı katı ötelenme oranı altında hasar oranları (Damage ratios for $1 \%$ roof drift)

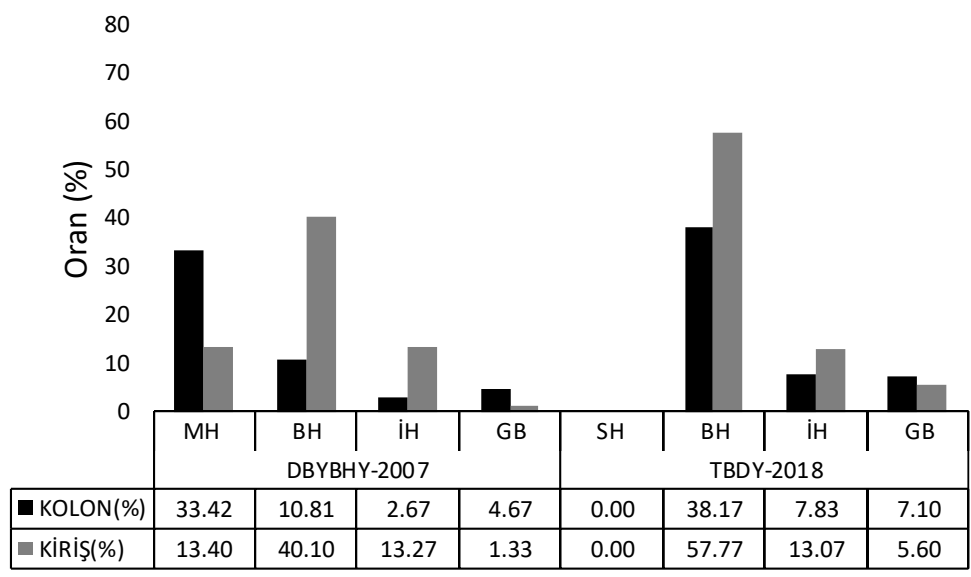

Şekil 10. \%1.5 Çatı katı ötelenme oranı altında hasar oranları (Damage ratios for $1.5 \%$ roof drift)

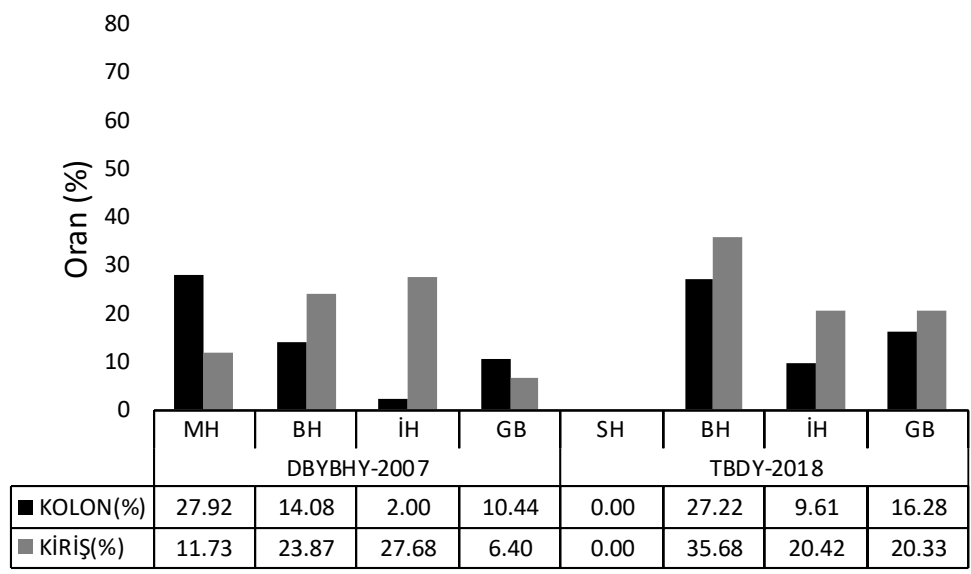

Şekil 11. \%2.0 Çatı katı ötelenme oranı altında hasar oranları (Damage ratios for $2 \%$ roof drift) 

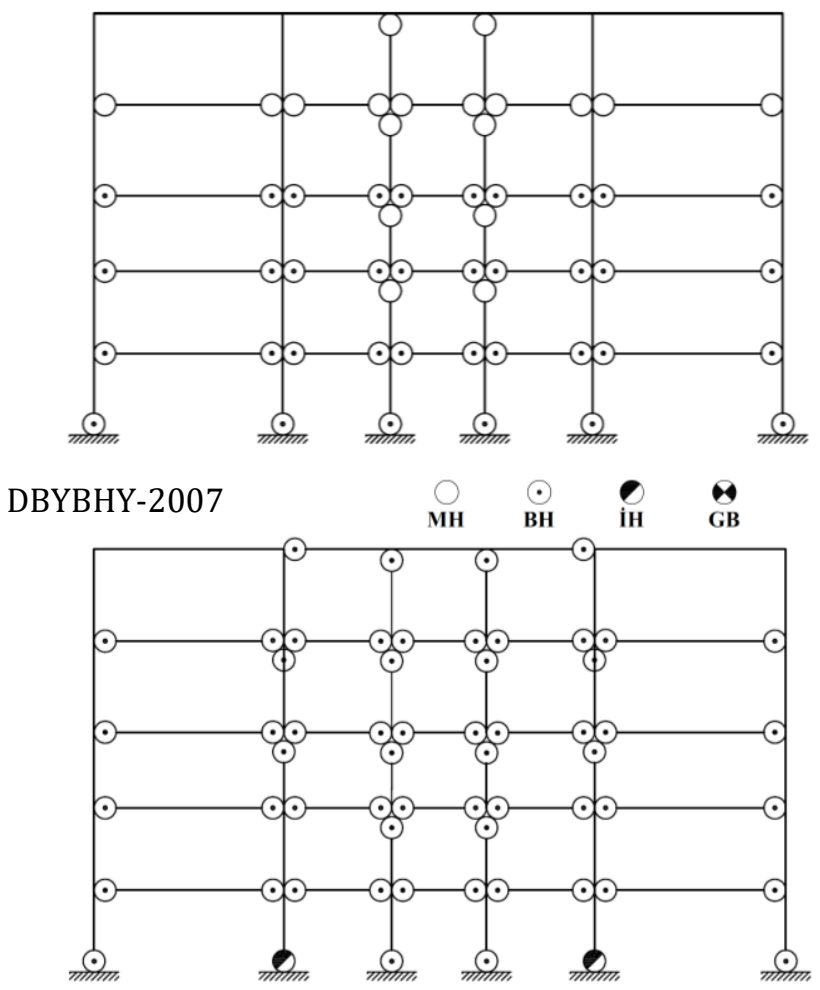

TBDY-2018

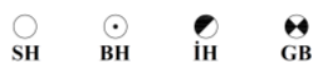

Şekil 12. Model $2 \% 1.0$ çatı katı ötelenme oranı için plastik mafsal dağılımı (Distrubition of plastic hinges for Model 2 at $1 \%$ roof drift)
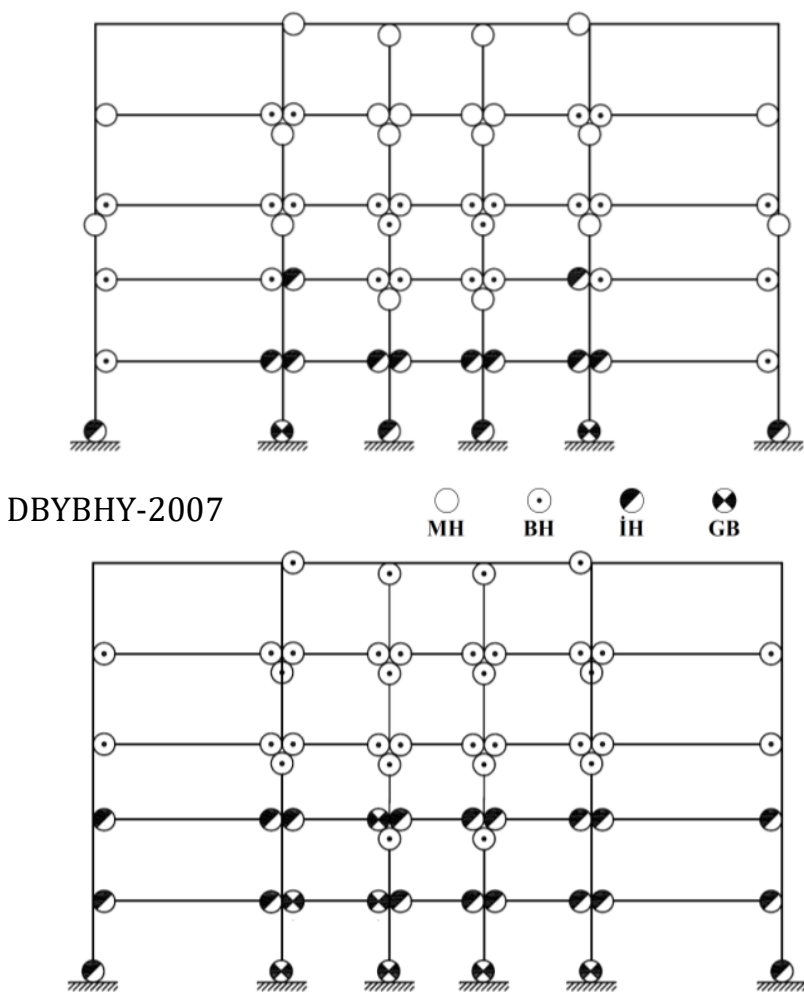

TBDY-2018

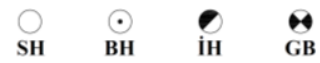

Şekil 13. Model $2 \% 1.5$ çatı katı ötelenme oranı için plastik mafsal dağılımı (Distrubition of plastic hinges for Model 2 at $1.5 \%$ roof drift) 


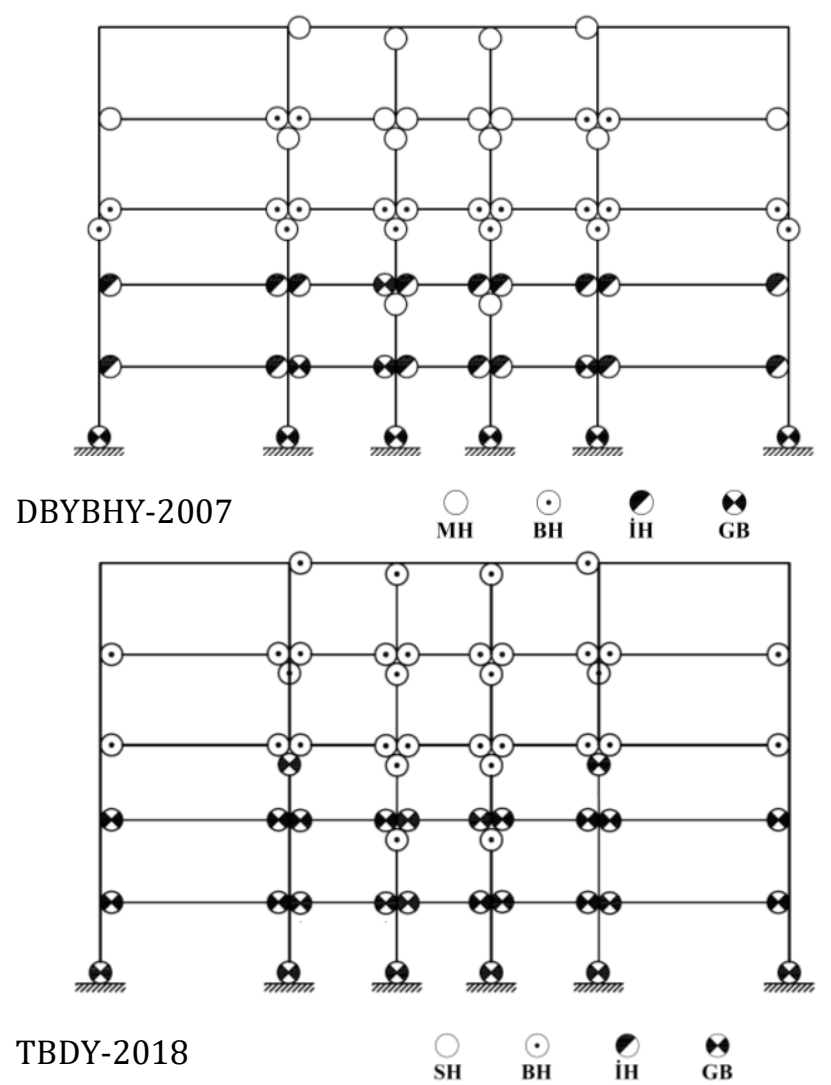

Şekil 14. Model $2 \% 2.0$ çatı katı ötelenme oranı için plastik mafsal dağılımı (Distrubition of plastic hinges for Model 2 at $2.0 \%$ roof drift)

\section{Sonuç ve tartışma (Result and discussion)}

Gerçekleștirilen çalıșmada DBYBHY-2007 ve TBDY-2018 yönetmelikleri plastik mafsal hasar sınırları karşılaştırılmıştır. Bu kapsamda daha önce inşa edilmiş 5 adet betonarme bina bilgisayar ortamında modellenerek statik analizleri gerçekleştirilmiştir. Elde edilen sonuçlar değerlendirildiğinde her iki yönetmeliğin kesit hasar sınır tanımlarının büyük farklılıklar içerdiği görülmektedir. Hesaplanan performans sınır noktalarına daha erken ulaşılmış olması nedeniyle TBDY-2018'in daha tutucu sonuçlar verdiği söylenebilir. TBDY-2018 Sınırlı Hasar performans düzeyine karşılık gelen çatı katı deplasman değeri DBYBHY-2007 Hemen Kullanım performans düzeyine göre ortalama \%100 daha düşük hesaplanmıştır. Kontrollü Hasar ve Göçme Öncesi performans düzeylerine de Can Güvenliği ve Göçmenin Önlenmesi performans düzeylerine göre sırasıyla \%25 ve \%33 daha düşük deplasman değerleri altında ulaşılmaktadır. Dikkat çeken bir diğer nokta da Sınırlı Hasar performans düzeyine sistemin akma noktasından önce ulaşılmış olmasıdır. DBYBHY-2007'de kolon çatlamış kesit rijitlik katsayıları eksenel yük oranına bağlı olarak hesaplanmaktayken TBDY-2018'de tüm kolon elemanlar için 0.70 değeri kullanılmaktadır. Özellikle eksenel yük oranının azaldığı üst katlarda her iki yönetmelik için hesaplanan eğilme rijitlikleri arasında farklar artmaktadır. DBYBHY-2007 kriterlerine göre modellenen binalarda baskın mod titreşim periyotları ortalama \%5.5 daha yüksek hesaplanmıştır. Eğilme rijitliğindeki değişime bağlı olarak kapasite eğrilerinin eğimi ve akma noktasına ulaşan eleman sayıları da farklılık göstermektedir. Hasar sınırlarına daha düşük deplasman düzeylerinde ulaşılması nedeniyle DBYBHY-2007 kriterlerine göre yeterli düzeyde olan bir yapının TBDY-2018 performans kriterlerini sağlamama ihtimali bulunmaktadır.

\section{Çıkar Çatışması (Conflict of Interest)}

Yazarlar tarafından herhangi bir çıkar çatışması beyan edilmemiştir. No conflict of interest was declared by the authors.

\section{Kaynaklar (References)}

ABYBHY, 1998. Afet Bölgelerinde Yapılacak Binalar Hakkında Yönetmelik, Bayındırlık ve İskân Bakanlığı, Ankara.

Balıkçı, İ., 2019. Mevcut Binaların Deprem Performanslarının 2007 ve 2018 Deprem Yönetmeliklerine Göre Değerlendirilmesi, Yüksek Lisans Tezi, Pamukkale Üniversitesi, Denizli.

DBYBHY, 2007. Deprem Bölgelerinde Yapılacak Binalar Hakkında Yönetmelik, Bayındırlık ve İskan Bakanlı̆̆ı, Ankara. 
Elçi, H., Göker, K.A., 2018. Deprem Yönetmeliklerinin (TDY 2007 ve TBDY 2018) Betonarme Kolonların Deprem Performansı Açısından Karşılaștırılması, International Journal of Scientific and Technological Research (Online), 4(6), 9-21.

Eldemir, O., 2019. DBYBHY-2007 ve TBDY-2018 Yönetmeliklerinin Mevcut Yapıların Sismik Davranış Özellikleri Açısından Karşılaştırılması, Yüksek Lisans Tezi, Pamukkale Üniversitesi, Denizli.

Eurocode 8, 2004. Design of Structures for Earthquake Resistance-Part 3: Assessment and Retrofitting of Buildings, European Committee for Standardization, Brussels.

Foroughi, S., Jamal, R., Yüksel, S.B., 2020. Şekil Değiștirme Esaslı Hasar Sınırlarının Belirlenmesinde Sargı Donatısının Ve Eksenel Yükün Etkisi, Mühendislik Bilimleri ve Tasarım Dergisi, 8(4), 1042-1052.

İnel M., Özmen H.B., 2006. Effects Of Plastic Hinge Properties in Nonlinear Analysis of Reinforced Concrete Buildings, Engineering Structures, 28(11), 1494-1502.

Korkmaz, K.A., Düzgün, M., 2006. Statik Artımsal İtme Analizinde Kullanılan Yük Dağılımlarının Değerlendirilmesi, İMO Teknik Dergi, 255, 3873-3878.

Kumbasaroğlu, A., 2020. Effect of Anchor Bars on Seismic Behavior of Infilled Walled Frames. KSCE Journal of Civil Engineering, 24(10), 2980-2992.

Mander J.B., Priestley M.J.N., Park R., 1988. Theoretical Stress-Strain Model for Confined Concrete, ASCE: Journal of Structural Engineering, 114(8), 1804-1826.

Özmen, H.B., 2011. Düşük Ve Orta Yükseklikteki Betonarme Yapıların Deprem Performanslarını Etkileyen Faktörlerin İrdelenmesi, Doktora Tezi, Pamukkale Üniversitesi, Denizli.

Özmen, H.B., İnel, M., Şenel Ş.M., Kayhan A.H., 2015. Load carrying system characteristics of existing Turkish RC building stock, International Journal of Civil Engineering, 13(1), 76-91.

Safkan, I., 2012. Comparison of Eurocode 8 and Turkish Earthquake Code 2007 for Residential RC Buildings in Cyprus, Proceedings of the 15th Conference on Earthquake Engineering, Lizbon, Portekiz.

CSI, 2018. SAP2000 Ultimate, Integrated Finite Element Analysis and Design of Structures, Version 20.0.0, Computers and Structures Inc., Berkeley, CA, USA.

Semap, 2008. Sargı Etkisi Modelleme Analiz Programı; Tubitak Proje No:105M024.

Sucuoğlu, H., 2006. 2007 Deprem Yönetmeliği Performans Esaslı Hesap Yöntemlerinin Karşılıklı Değerlendirilmesi, Türkiye Mühendislik Haberleri, 4(5), 24-36.

Sümer, Y., Hamsici, M., 2020. Çok Katlı Betonarme Binalarda 2018 Deprem Yönetmeliği İle Tanımlanan Spektrum Eğrilerinin Etkisi, Academic Platform Journal of Engineering and Science 8(2), 349-354.

TBDY, 2018. Türkiye Bina Deprem Yönetmeliği, Afet ve Acil Durum Yönetimi Bașkanlı̆̆ı, Ankara.

Ulutaș, H., 2019. DBYBHY (2007) ve TBDY (2018) Deprem Yönetmeliklerinin Kesit Hasar Sınırları Açısından Kıyaslanması Avrupa Bilim ve Teknoloji Dergisi, 17, 351-359. 